\title{
INVESTIGATION ON THERMAL COMFORT CHARACTERISTICS OF REGENERATED BAMBOO AND COTTON WOVEN STRUCTURED FABRICS
}

\author{
Zamir Ahmed Abro1*, Nanliang Chen ${ }^{1}$, Zhang Yifan ${ }^{1}$, Hong Cheng-Yu², Abdul Malik Rehan Abassi ${ }^{3}$, \\ Altaf Ahmed Simair ${ }^{4}$, Rafique Ahmed ${ }^{1}$, Azmat Hussain ${ }^{5}$
}

1Department of knitting and clothing, college of Textile, Donghua University, Shanghai, 201620, China

${ }^{2}$ Department of Civil Engineering, Shanghai University, Shanghai 200444, China.

${ }^{3}$ Department of Textile Engineering, BUTIEMS, Quetta, 87300, Pakistan

${ }^{4}$ College of Chemistry, Chemical Engineering and Biotechnology, Donghua University, Shanghai, 201620, China

${ }^{5}$ Department of Textiles Engineering, College of textile, Donghua University, Shanghai, 201620, China

\section{Abstract:}

In this research work, thermal properties of plain woven fabrics generated from regenerated bamboo and cotton fiber blended yarns were investigated. Seven mixtures of fiber (100\% bamboo, 100\% cotton, 10:90 bamboo: cotton, 20:80 bamboo: cotton, 30:70 bamboo: cotton, 40:60 bamboo: cotton and 50:50 bamboo: cotton) were developed to create 60 Tex ring spun yarn. The warp yarns were used as $100 \%$ regenerated bamboo and the bamboo: cotton blends were used alternatively in weft to produce plain woven fabrics. The plain structured woven fabrics show eminent thermal comfort properties with the blending of regenerated bamboo fibers. The air permeability of $100 \%$ regenerated bamboo fiber was recorded higher than the compared blends; the increased key factor contents of bamboo changed the air properties of the fabric. Furthermore, plain woven fabric of bamboo/cotton (50/50) has shown greater thermal conductivity and heat retention properties. The work reported in this paper is ensuring highpoints of thermal comfort properties of regenerated bamboo (100\%) and cotton (100\%) with plain woven structured fabrics, and potentially, the fabrics can be used for winter suiting apparel products.

\section{Keywords:}

Ring spun yarn, plain woven fabrics, air permeability, thermal conductivity

\section{Introduction}

The use of blended fibers is a very common practice for spinning industries. Blending is primarily done to enhance the properties of the resultant product and to optimize the cost of the raw material [1,2]. The characteristics of blended yarns basically depend on the properties of the constituent fibers and their compatibility. Furthermore, the composition of fibers in terms of the percentage of the blending material plays a very significant role. It's a proven fact that the stronger component must be mixed at least by a certain proportion to achieve best results in terms of tensile properties. Thermal relaxation properties of fabric, especially natural materials, have enhanced the interest of researchers in this fabric in modern times. The appropriateness of clothing fabric fundamentally depends on the comfort features that comprise the thermal properties, but the shortage of natural fibers such as of cotton fiber in cotton growing countries is increasing due to the highly in demand comfort clothing. The main reasons for the reduction in production [3-5] are the shortage of water for agriculture, land for agriculture (in large populated countries), a droughtlike situation in the absence of monsoon rains, energy crisis, and environmental feasibility. The experts have deeply studied the mechanical properties of clothes to elaborate the right cloth for the wearers. In contrast to this, the comfort clothing is a way to pass heat and air across the structure of the fabric. During strenuous activities, the entire body generates a lot of heat [6-9] energy and the body temperature increases and perspiration is generated. When perspiration evaporates into the atmosphere, the body temperature decreases. So, the fabrics'/garments' material should have a quality to pass the perspiration to ensure comfort in the material or cloth. The properties of natural cotton and regenerated bamboo are similar in many aspects; the chemical and mechanical nature of cotton and bamboo are almost similar. Bamboo textile products have high demand in the market because of their antibacterial nature, biodegradable properties, high moisture absorption capacity, softness and UV productive capability. With its high moisture absorption capacity, breathability and fast drying behavior, bamboo fiber ensures comfort in various applications. Bamboo [10] fiber has the crystallite size similar to that of ramie, but larger than those of flax and cotton fibers. The researchers are finding particular natural cellulosic fibers to [11-13] complete with comfort properties $[14,15]$. These fiber blends have found potential in textile industries due to many properties, such as their comfort, warmness, coolness, touch feel, wear/end use [16] and anti-ultraviolet properties. The bamboo $100 \%$ woven fabrics $[2,15,17]$ has recorded higher air passage than the $70: 30 \%$ cotton bamboo in weft yarn because the cross-section of bamboo fiber is covered with various micro spaces. The high [18-21] composition of bamboo fabrics showed that these are water permeable, more absorbent, with more air passage within the structure of fabrics. High content bamboo fabrics and lower thermal resistance was also seen within cotton the structured 
fabrics. Linear densities [22] of the yarn and loop length in the knitted fabrics have an effect on the thermal comfort properties of the knitted structured fabrics. The $100 \%$ cotton fabrics have [23-27] higher air permeability and higher thermal resistance values matched with bamboo/cotton blended fabrics.

In this research work, the cotton and regenerated bamboo blends were produced under different blend ratios and yarn production (i.e., linear density and twist) parameters were kept constant. During the production of fabrics; the spun yarn blends were used in the weft direction and regenerated bamboo was used in warp direction under the same fabric construction parameters. The air permeability, thermal conductivity and heat retention properties were examined for accomplishing the research outcome.

\section{Materials and Methods}

\subsection{Material and its analysis}

In this study, raw materials, cotton and regenerated bamboo with defined physical properties were purchased from a wellknown internationally bamboo producing organization of Hangzhou, china. The fiber parameters are given in Table 1.

Table 1. Cotton- $100 \%$ and regenerated bamboo- $100 \%$

\begin{tabular}{|c|c|c|c|}
\hline Sample & $\begin{array}{c}\text { Fiber } \\
\text { length, } \\
\text { mm }\end{array}$ & $\begin{array}{c}\text { Fiber } \\
\text { Strength, } \\
\text { cN/tex }\end{array}$ & $\begin{array}{c}\text { Fiber } \\
\text { elongation, } \\
\text { (\%) }\end{array}$ \\
\hline Cotton 100\% & 26.4 & 7.27 & 5.65 \\
\hline Bamboo 100\% & 38.3 & 6.72 & 20.62 \\
\hline
\end{tabular}

Cotton $100 \%$ and regenerated bamboo $100 \%$ was mixed. $2 \mathrm{~kg}$ of each fiber was taken, and mixed ratios were calculated as per the requirements of the yarns. The following ratios were selected as per the requirements of the research work. The ratios for yarn samples were (cotton 100\%, regenerated bamboo 100\%, bamboo: cotton 90:10, bamboo: cotton $80: 20$, bamboo: cotton 70:30, bamboo: cotton $60: 40$, bamboo: cotton 50:50) were mixed and calculated to feed the material to blow room and carding. The carding machine DHU-China was set at $20 \mathrm{~m} / \mathrm{min}$ and size of silver was set at $4.5 \mathrm{~g} / \mathrm{m}$ and twist arrangement was kept on S-twist. After carding machines, slivers were doubled in a drawing frame named as DSDr-01, China. The drawing machine was set at $10 \mathrm{~m} / \mathrm{min}$ and size of silver was set at $4.5 \mathrm{~g} / \mathrm{min}$ and twist arrangement was kept on S-twist. Then, the roving frame was used to produce the roving sliver on DSRo-01, China. The machine speed was set at $500 \mathrm{rot} / \mathrm{m}$ and count of roving was fixed at 0.8 hanks. The seven yarn samples (60 Tex) were produced in yarns manufacturing machine DssP-01, China. The yarn parameters were kept under the same twist and linear density. The spinning frame parameters were also kept constant such as twist at $500 \mathrm{tpm}$ $(\mathrm{no} / \mathrm{m})$ and spindle speed at $10,000 \mathrm{rot} / \mathrm{min}$. The yarn samples were tested on different testing machines. The ASTM standard method ASTM D1907 - 07 was employed. The lea method was used to calculate the linear density. The yarn mass variation was tested on electronic tester FB-198. The delivery speed was set at $10 \mathrm{~m} / \mathrm{min}$ and total 400 meters of length of yarns were used for each sample. The 10 tests were performed for each individual sample. The tensile strength of yarn samples was calculated on Electronic tester XL-2. Total 10 tests were selected and used for testing each individual sample and some of the yarn properties are given in Fig 1, Fig 2 and Table 2. The warp yarns were used as $100 \%$ regenerated bamboo and weft yarns were used alternatively with blends of regenerated bamboo/cotton for the manufacturing of complete plain-woven fabric samples. (The fabric constructions are given in Table 3.) The woven fabric samples were produced from one private textile weaving mill in Zhejiang province. The plain-woven fabrics were examined and has an average warp of $285 \mathrm{~g} / \mathrm{m}^{2}$ and weft count 60 Tex, ends/inch 224 and picks/inch 112, respectively. All fabrics construction parameters were kept exactly the same during the fabric manufacturing process.

\subsection{Methods of fabric testing}

The thermos labo-II instrument was used to measure thermal conductivity, thermal resistance and sample thickness to calculate all the measurement parameters. The air resistances value plain woven fabrics were measured with the help of (KES-FB5).

The Thermal Conductivity tester consists of T-box that was heated up to $25^{\circ} \mathrm{C}$ by covering it with a hot BT-box. The T-box was positioned over the sample of fabric, which was done with a block of insulating material as a flow of heat between fabrics and T-box was measured by an electronic instrument called Thermo labo II [28, 29].

The air permeability is determined by the rate of air flow passing perpendicularly through a known area of fabric and adjusted to achieve a prescribed air pressure differential between the two fabric surfaces. The ASTM D737-04 was followed for measuring the air permeability of the fabric samples [30]. Air permeability was measured by the YG (B) 4G1D-1 air permeability tester under accuracy level of $\pm 3 \%$ of the displayed value. The fabrics were cut into squares of $20 \mathrm{~cm} / \mathrm{square}$ then pressed by iron to get a smooth surface of the fabric and exact air passage within the fabric structures. The air permeability machine was calibrated on plunger number 5 and area of the test was $35 \mathrm{~cm}^{2}$. The unit of measurement was $1 \mathrm{R} / \mathrm{mm} / \mathrm{sec}$, where $R$ indicates the resistance of air passing in between air spaces of the fabric structures.

\section{Results and Discussion}

\subsection{Yarn properties}

The yarn mass variation is a measurement of yarn irregularities in mass per unit length of yarn. The given results of mass variation have examined the complete analysis of yarn quality and irregularity. The irregularity $(\mathrm{U} \%)$ is the mass variation from the given standards of unit length of materials due to improper fiber circulation with yarn. The coefficient of variation $\mathrm{CV} \%$ is the statistical analysis of the yarn samples. The coefficient of 


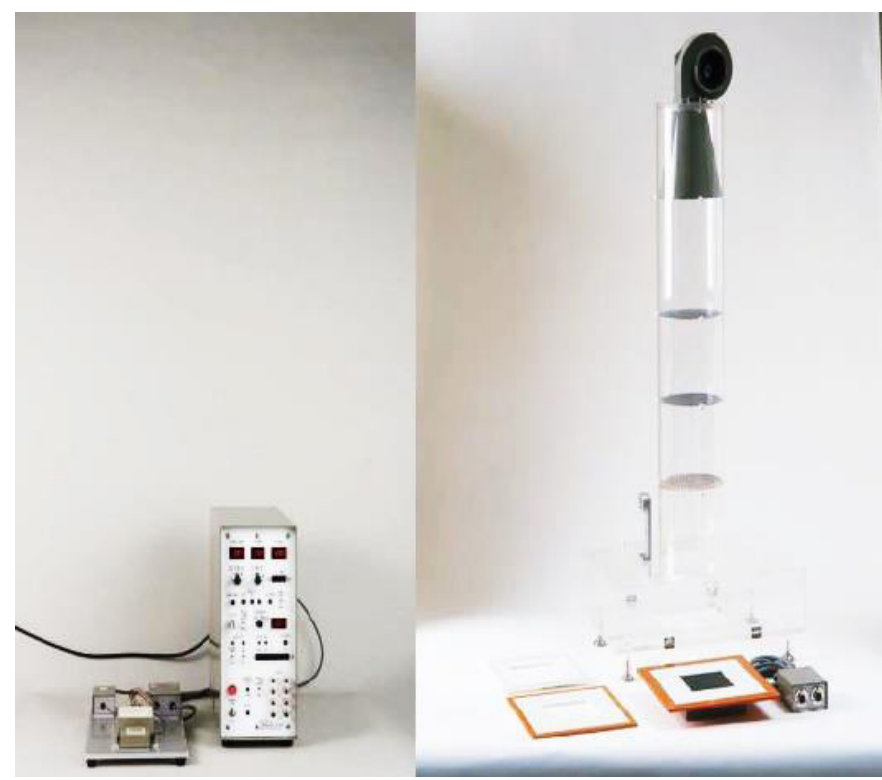

Figure 1. Testing region of Thermo labo-II tester

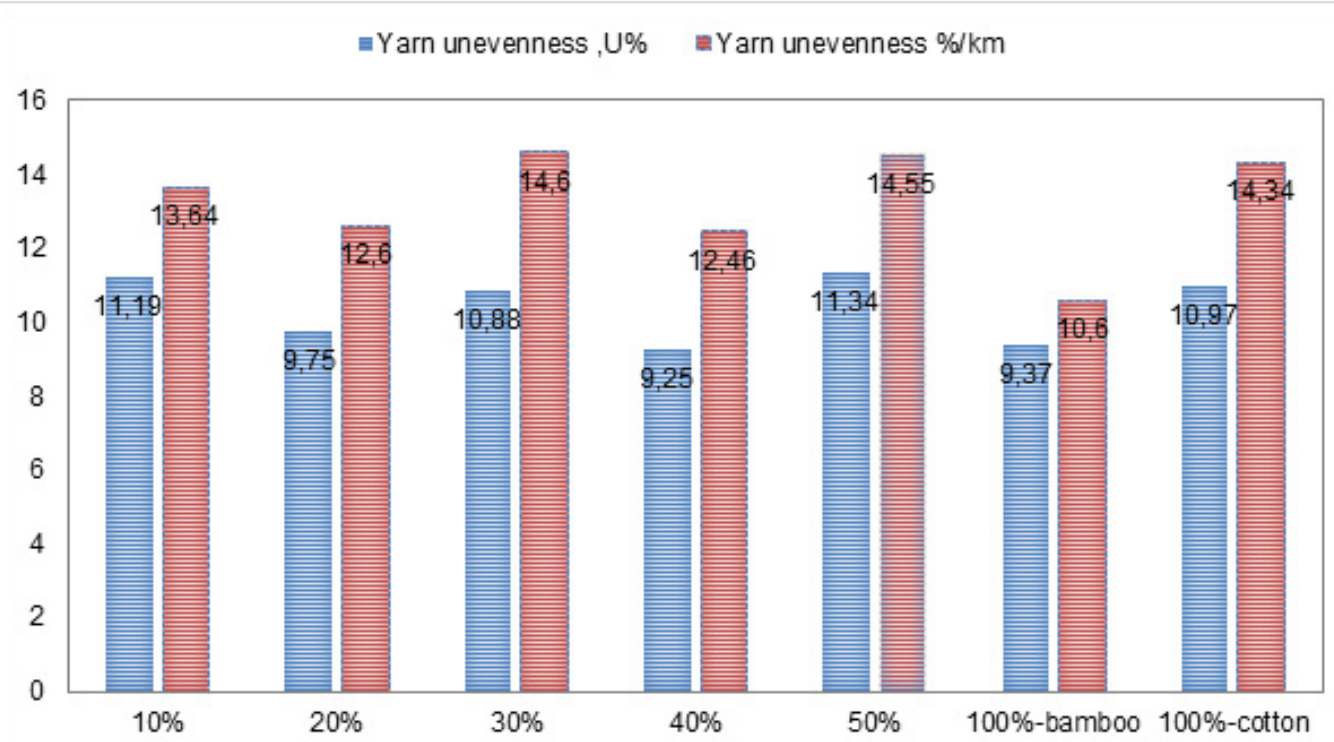

Figure 2. Unevenness ( $\mathrm{U} \%$ ) and Coefficient of variation (cv \%) properties of 60 Tex cotton and bamboo/ cotton blends with different blend ratios

Table 2. Yarn properties

\begin{tabular}{|c|c|c|c|c|c|c|c|}
\hline Property & $\begin{array}{c}100 / 0 \\
\text { bbo }\end{array}$ & $\begin{array}{c}90 / 10 \\
\text { co/bbo }\end{array}$ & $\begin{array}{c}80 / 20 \\
\text { co/bbo }\end{array}$ & $\begin{array}{c}70 / 30 \\
\text { co/bbo }\end{array}$ & $\begin{array}{c}60 / 40 \\
\text { co/bbo }\end{array}$ & $\begin{array}{c}50 / 50 \\
\text { co/bbo }\end{array}$ & $\begin{array}{c}100 / 0 \\
c o\end{array}$ \\
\hline Count of yarn. Tex & 59.98 & 60.02 & 59.99 & 59.88 & 60.02 & 60.1 & 60.05 \\
\hline Thin places, $-50 \% / \mathrm{km}$ & 0.0 & 0.0 & 0.0 & 0.0 & 0.0 & 0.0 & 0.0 \\
\hline Thick place, $+50 \% / \mathrm{km}$ & 16 & 26 & 213 & 293 & 106 & 213 & 40 \\
\hline Neps, $+200 \% / k m$ & 36 & 80 & 266 & 240 & 133 & 320 & 80 \\
\hline Neps, $+280 \% / \mathrm{km}$ & 0 & 53 & 160 & 160 & 106 & 160 & 0 \\
\hline Force at Break, cn & 770.2 & 912.32 & 867.83 & 850.73 & 739.4 & 605.2 & 809.4 \\
\hline Modulus, cn/dtex & 18.31 & 46.57 & 37.24 & 37.54 & 34.37 & 32.29 & 39.08 \\
\hline
\end{tabular}

$\mathrm{co}=$ cotton, $\mathrm{bbo}=$ bamboo 
Table 3. Fabric Specifications

\begin{tabular}{|c|c|c|c|c|c|c|c|c|}
\hline \multirow{2}{*}{ Sr.no } & \multicolumn{2}{|c|}{ Sample Specification } & $\begin{array}{c}\text { Weight } \\
\left(\mathbf{g} / \mathbf{m}^{2}\right)\end{array}$ & \multicolumn{2}{|c|}{ Count (Tex) } & Ends/inch & Picks/inch & $\begin{array}{c}\text { Fabrics } \\
\text { Structure }\end{array}$ \\
\cline { 2 - 9 } & \multicolumn{2}{|c|}{ Warp Weft } & & Warp & Weft & Warp & Weft & Warp Weft \\
\hline 01 & bbo-100 & bbo -100 & 280 & 60 & 60.05 & 224 & 112 & Plain \\
\hline 02 & bbo-100 & co/bbo,90/10 & 281 & 60 & 60.02 & 224 & 112 & Plain \\
\hline 03 & bbo-100 & co/bbo,80/20 & 285 & 60 & 59.99 & 224 & 112 & Plain \\
\hline 04 & bbo-100 & co/bbo,70/30 & 284 & 60 & 59.88 & 224 & 112 & Plain \\
\hline 05 & bbo-100 & co/bbo,60/40 & 281 & 60 & 60.02 & 224 & 112 & Plain \\
\hline 06 & bbo-100 & co/bbo,50/50 & 281 & 60 & 60.01 & 224 & 112 & Plain \\
\hline 07 & bbo-100 & co- 100 & 286 & 60 & 59.98 & 224 & 112 & Plain \\
\hline
\end{tabular}

variation normally defines the number of variations within the yarn structure. It can be expressed as:

Coefficient of variation (CV) $\%=($ standard deviation/average $)$ $x 100$.

It is clearly seen that yarn irregularity varies with blend ratios of bamboo and cotton.

The unevenness varies with an increase or decrease in the portion of bamboo fiber, as shown in Fig 2.

It was seen that $\mathrm{CV} \%$ of per kilometer of ring spun yarn has shown minor variation, which is considerable during the weaving and dyeing of textile fabrics. The cotton $100 \%$ can be shown as single yarn strength. The single yarn strength and modulus increase with a decrease in the percentage of bamboo fiber. The bamboo fiber has more elongation than the cotton fiber, and hence, the bamboo blend yarn shows more elongation (as shown in Fig 3).

\subsection{Thermal Conductivity}

The thermal properties of some selected woven fabric structures, namely the plain-woven fabrics from $100 \%$ regenerated bamboo and $100 \%$ cotton, are shown in Figure 4. The results reveal that both fiber types showed significant variation and differences. The thermal conductivity provided by a fabric depends on the fiber type, fabric thickness, fiber arrangement and the compressibility of the fabric structure. The mechanism of heat transfer involves dry heat transmission through conduction, convection, and radiation. Latent heat transfer due to water vapor transport and liquid water transport also determines the thermal properties. Thermal conductivity values have been recorded as $100 \%$ higher for regenerated bamboo than another bamboo: cotton blends. It was observed that thermal conductivity increased with an increase in the content of regenerated bamboo fibers.

The bamboo fibers are good conductors of heat when blended with cotton and can conduct good heat properties that give cool

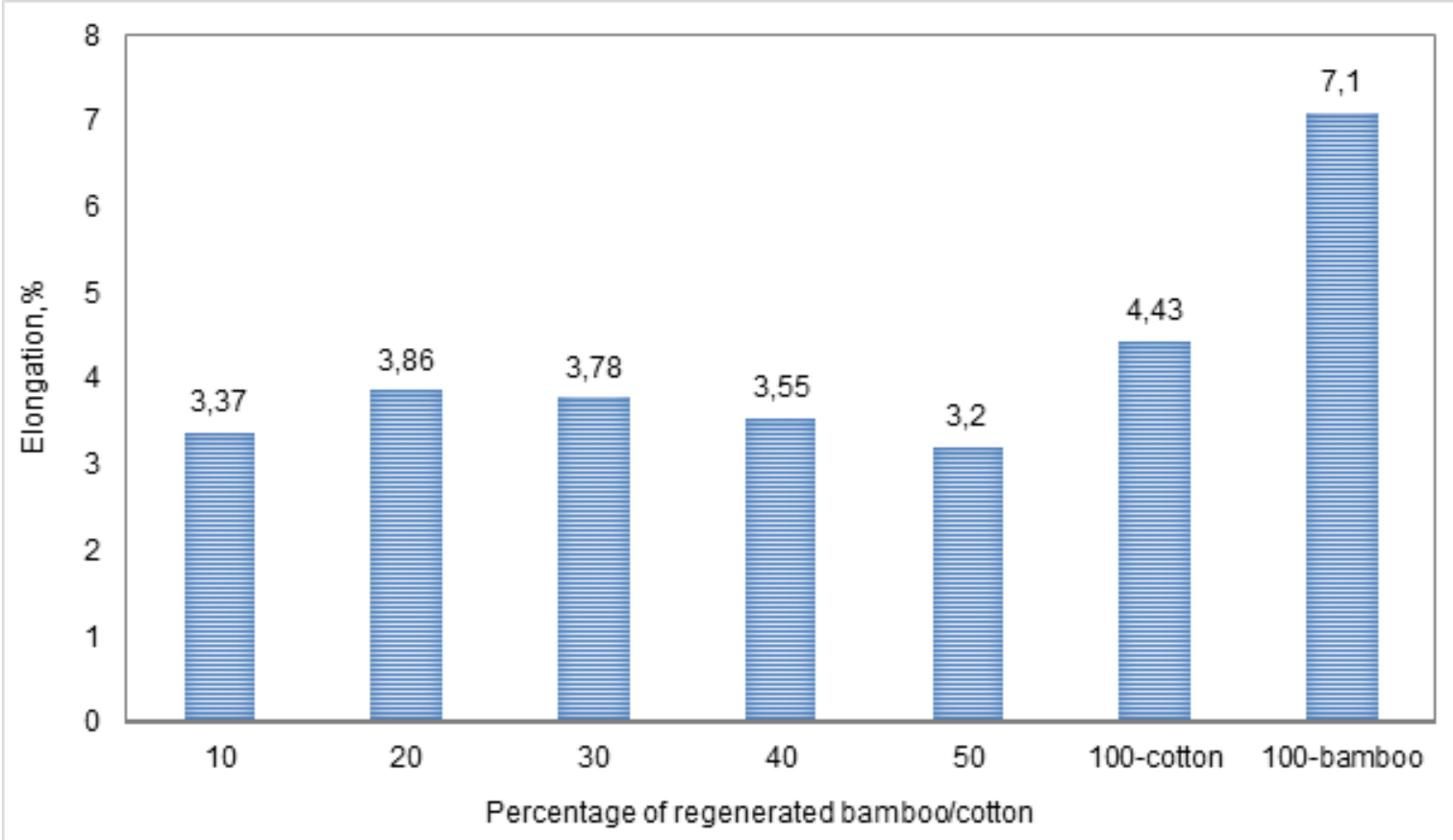

Figure 3. Elongation (\%) properties of 60 tex cotton/bamboo blends with different blend ratios 
feelings to the wearer in summers. But the end use of such fabrics depends on the size of yarn, type of weave and weave structure.

\subsection{Air Permeability}

The resistance of a fabric to the flow of air is a determinant of the primary warm/cool feeling when the fabric/garment is worn. The higher the air flow value, the better will be the intensity of the warm and cool feeling of fabrics, which means that higher air is passed in per unit area of fabric. The consequence of air permeability on comfort properties of woven fabric is influenced more when the speed of air is high, for example, in stormy weather conditions.
The bamboo $100 \%$ fabrics allowed more air to pass through, as compared to other blends; however, the blends of bamboo and cotton recorded more air permeability values, comparatively; the fabrics contained bamboo- $60 \%$ and cotton- $40 \%$ ( see Fig 5). The air permeability increased due to their longer and smoother bamboo fiber as compared to cotton. It was also possible due to the large diameter of the fiber with the low packing density of the yarn. Bamboo fibers, being smooth, circular and coarser as compared to cotton fibers, also assist the easy passage of air through the yarn cross-section, which results in higher air permeability. The result showed that the air permeability decreased with respect to an increase in the cotton component. The air permeability results reveal that the

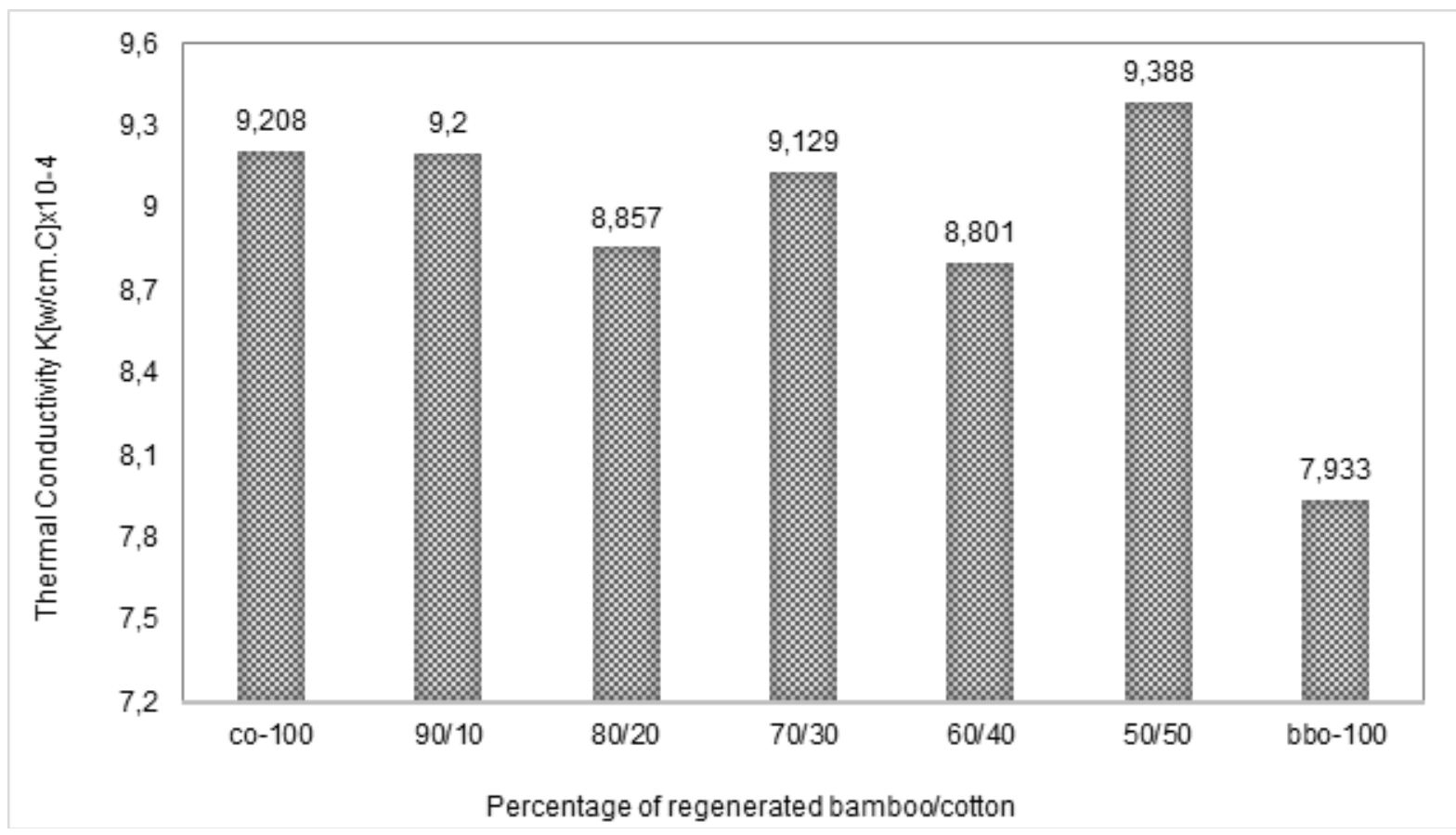

Figure 4. Thermal conductivity of woven fabrics made of bamboo/cotton blends with different blend ratios

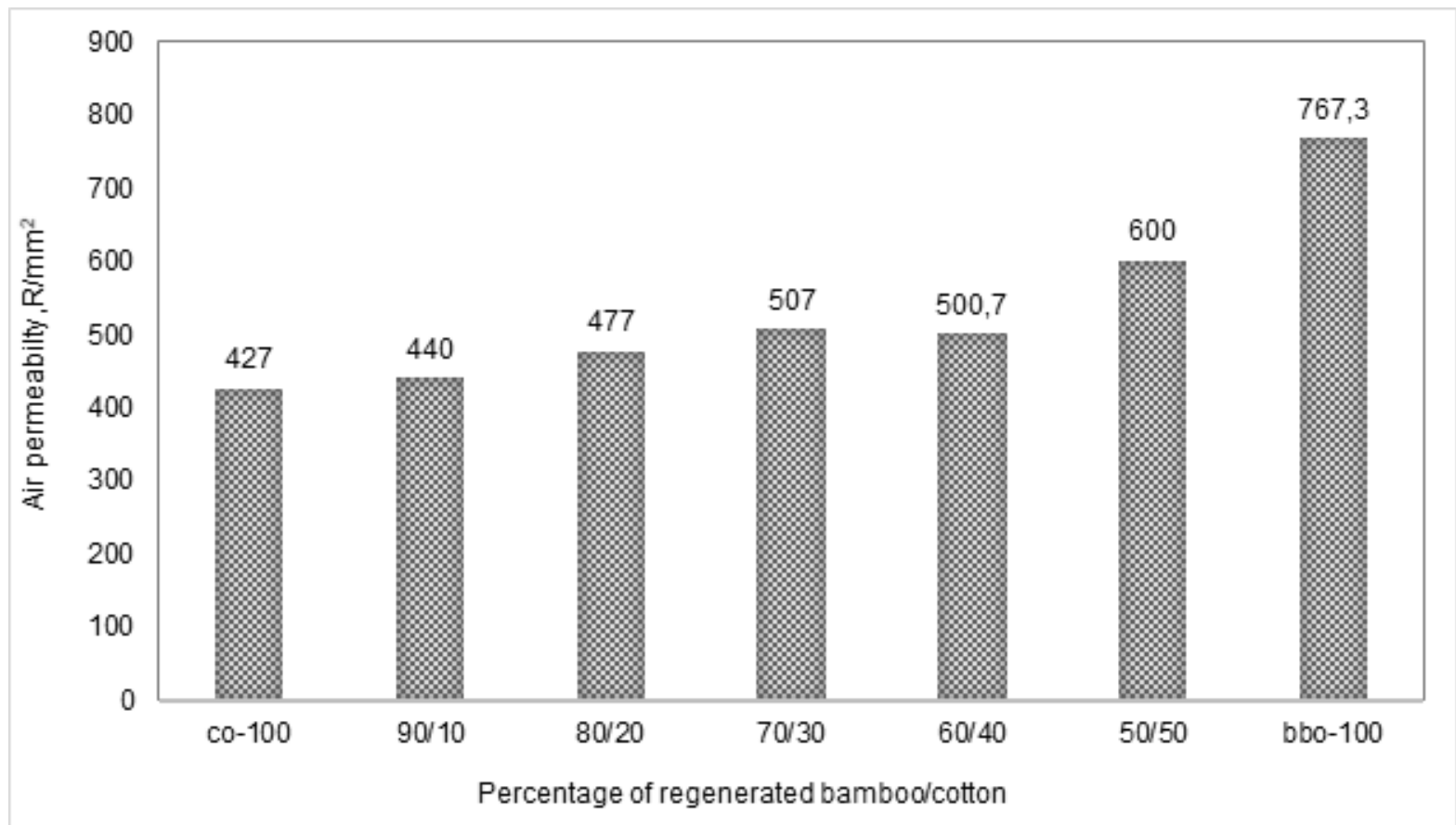

Figure 5. Air permeability of woven fabric made of bamboo/cotton blends with different blend ratios 
fabrics made from cotton and bamboo blends are more suitable for winter dress material. It can be also used for summer suiting if the construction of the fabric, size of yarns and other related parameters may be changed; the results provided for the comfort parameters of woven fabrics to be made suitable to meet the requirements of woven fabrics.

\subsection{Heat Retention}

Heat retention percentage of cotton- $100 \%$ and bamboo/cotton $50 / 50 \%$ fabrics were seen dominant than all other blends, as shown in Figure 6.

The bamboo/cotton, $60 / 40 \%$ and bamboo/cotton $70 / 30 \%$ blended fabrics gave less heat retention. Based on the thermal comfort results, thermal conductivity and heat retention can provide the desired protection to the human body against climatic fluctuations. This kind of blends will be more comfortable for human beings and give them warm and cool comfort satisfaction.

\section{Conclusion}

The comfort properties of plain woven structures prepared from natural and regenerated bamboo cellulosic fibers have been studied and investigated. The yarns made from bamboo fibers have the lower values of initial modulus and elongation like cotton yarns. In order to produce blended woven fabrics, the warp yarns were used as $100 \%$ regenerated bamboo and weft yarns were inserted alternatively with blended yarns of regenerated bamboo/cotton. The results obtained are very promising and each plain-woven fabric showed the desired thermal comfort properties with blending of regenerated bamboo. The air permeability of $100 \%$ regenerated bamboo was recorded as excellent in comparison of other blends. Overall, the fabrics with greater bamboo content are more bearable to air passages. The research work is concluded with high points of thermal comfort properties of regenerated bamboo- $100 \%$ and cotton- $100 \%$ with plain woven fabrics. The content of bamboo showed dominant changes in comfort properties, such as thermal conductivity and heat retention. The blend ratio of bamboo-50\% and cotton- $50 \%$ has shown valuable thermal conductivity and heat retention properties for a kind of fabric that could be chosen for winter suiting apparel.

\section{Acknowledgment}

The authors are greatly thankful to the authorities of key laboratory of knitting and clothing, College of Textiles, Donghua University, Shanghai, China and we would like to express our gratitude to Dr. Chen Nanliang and Dr. Zhang Yifan for providing valuable guidance, sincere suggestions and financial support.

\section{References}

[1] Prakash, C., G. Ramakrishnan, and C. Koushik, Effect of blend ratio on the quality characteristics of bamboo/ cotton blended ring spun yarn. Fibres \& Textiles in Eastern Europe, 2011. 19(6): p. 38-40.

[2] Özdil, N., A. Marmaralı, and S.D. Kretzschmar, Effect of yarn properties on thermal comfort of knitted fabrics. International journal of Thermal sciences, 2007. 46(12): $p$. 1318-1322.

[3] Islam, N., Environmental issues in Bangladesh: an overview. Pakistan journal of social sciences, 2005. 3(4): p. 671-679.

[4] Qureshi, A.S., Climate change and water resources management in Pakistan. Climate change and water resources in South Asia. AA Balkema Publishers, Leiden, 2005: p. 197-230.

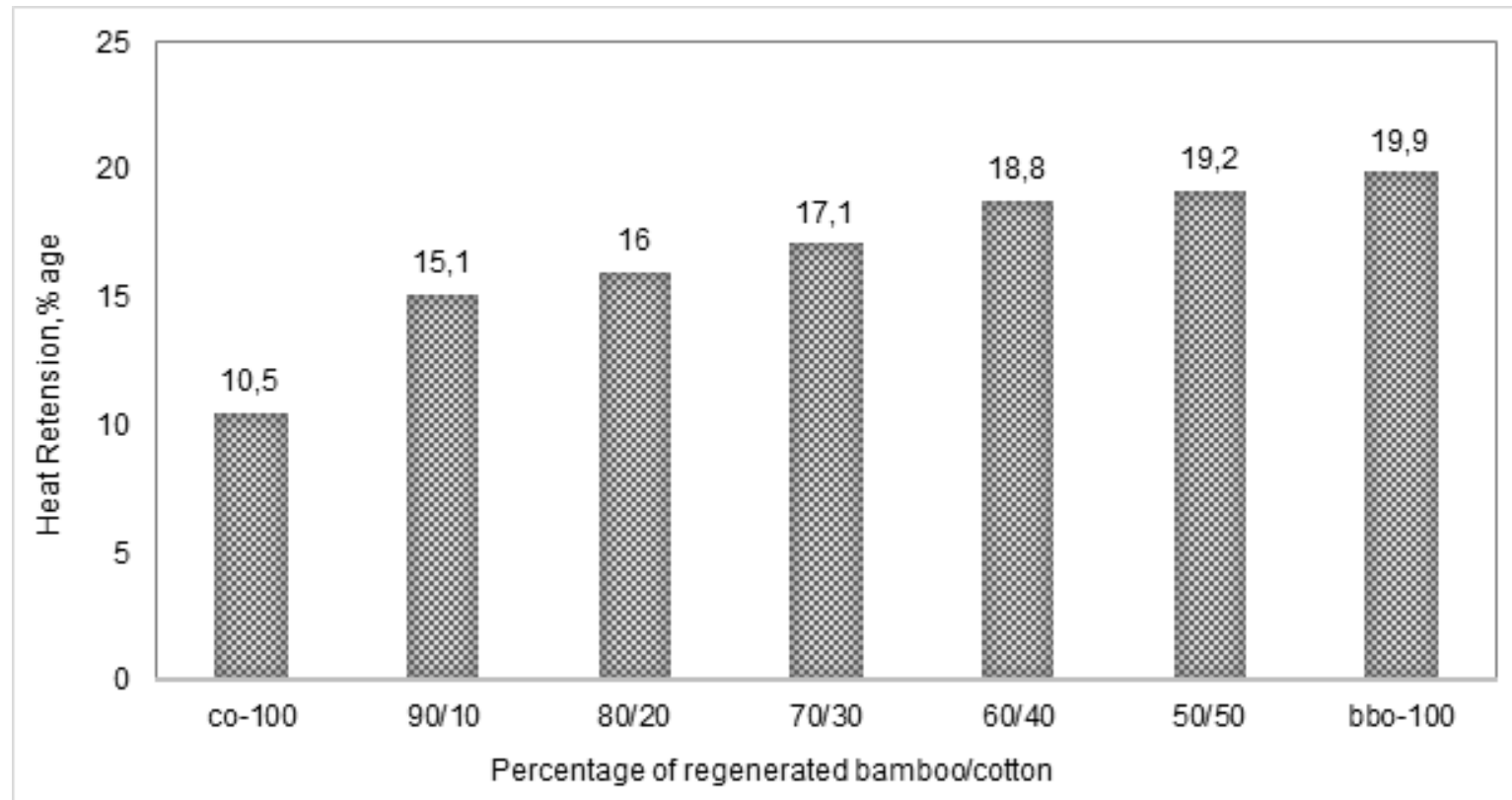

Figure 6. Heat retention percentage of woven fabrics made of bamboo/cotton blends with different blend ratio 
[5] Mishra, M., G.R. Panda, and B. Padhi, Sustaining Indian Agriculture in the Era of Climate Change, in Genetics, Biofuels and Local Farming Systems. 2011, Springer. p. 231-250.

[6] Huang, J., Sweating guarded hot plate test method. Polymer testing, 2006. 25(5): p. 709-716.

[7] Chan, A.P., et al., The development of anti-heat stress clothing for construction workers in hot and humid weather. Ergonomics, 2016. 59(4): p. 479-495.

[8] Li, Y., The science of clothing comfort. Textile progress, 2001. 31(1-2): p. 1-135.

[9] Afzal, A., et al. Influence of fabric parameters on thermal comfort performance of double layer knitted interlock fabrics in the 12th Asian Textile Conference, China Textile Engineering Society, Shanghai, China. 2013.

[10] He, J., Y. Tang, and S.-Y. Wang, Differences in Morphological Characteristics of Bamboo Fibres and other Natural Cellulose Fibres: Studies on X-Ray Diffraction, Solid State^ $1^{\wedge}$ 3C-CP/MAS NMR, and Second Derivative FTIR Spectroscopy Data. Iranian Polymer Journal, 2007. 16(12): p. 807.

[11] Grosberg, P., The mechanical properties of woven fabrics part ii: the bending of woven fabrics. Textile Research Journal, 1966. 36(3): p. 205-211.

[12] Das, $A$. and S. Ishtiaque, Comfort characteristics of fabrics containing twist-less and hollow fibrous assemblies in weft. Journal of Textile and Apparel, Technology and Management, 2004. 3(4): p. 1-7.

[13] Frydrych, I., G. Dziworska, and J. Bilska, Comparative analysis of the thermal insulation properties of fabrics made of natural and man-made cellulose fibres. Fibres and Textiles in Eastern Europe, 2002. 10(4): p. 40-44.

[14] Stannard, C.R. and E.A. Sanders, Motivations for participation in knitting among young women. Clothing and Textiles Research Journal, 2015. 33(2): p. 99-114.

[15] Chen, Q., et al., The Comfort Properties of Two DifferentialShrinkage Polyester Warp Knitted Fabrics. Autex Research Journal, 2016. 16(2): p. 90-99.

[16] Yi, L.J.Y.L.W., Application and Property Test of Bamboo Cellulose Fibre [J]. Cotton Textile Technology, 2004. 2: $p$. 012.

[17] Sekerden, F., Effect of fabric weave and weft types on the characteristics of bamboo/cotton woven fabrics. Fibres \& Textiles in Eastern Europe, 2011. 19: p. 47-52.
[18] Erdumlu, N. and B. Ozipek, Investigation of regenerated bamboo fibre and yarn characteristics. Fibres \& Textiles in Eastern Europe, 2008. 16(4): p. 69.

[19] Chidambaram, P. and R. Govindan, Influence of blend ratio on thermal properties of bamboo/cotton blended woven fabrics. Silpakorn U Science \& Technology Journal, 2012. 6(2): p. 49-55.

[20] Ahmad, I., et al., Quality parameters analysis of ring spun yarns made from different blends of bamboo and cotton fibres. Journal of Quality and Technology management, 2012. 8(1): p. 1-12.

[21] Majumdar, A., et al., Properties of ring-spun yarns made from cotton and regenerated bamboo fibres. Indian Journal of Fibre and Textile Research, 2011. 36(1): p. 18.

[22] Chidambaram, P., R. Govindan, and K.C. Venkatraman, Study of thermal comfort properties of cotton/regenerated bamboo knitted fabrics. African Journal of Basic \& Applied Sciences, 2012. 4(2): p. 60-66.

[23] Prakash, C., G. Ramakrishnan, and C.V. Koushik, A study of the thermal properties of single jersey fabrics of cotton, bamboo and cotton/bamboo blended-yarn vis-a-vis bamboo fibre presence and yarn count. Journal of thermal analysis and calorimetry, 2011. 110(3): p. 1173-1177.

[24] Li, L.-J., et al., Evaluation of properties of natural bamboo fiber for application in summer textiles. Journal of Fiber Bioengineering and Informatics, 2010. 3(2): p. 94-99.

[25] Li, L. and H. Yan, Tensile properties of regenerated bamboo yarn. Fibres \& Textiles in Eastern Europe, 2012. 20(1): $p$. 20-22.

[26] Nishi, Y., Measurement of thermal balance of man. Studies in environmental science, 1981. 10: p. 29-39.

[27] Roos, S., et al., Is unbleached cotton better than bleached? Exploring the limits of life-cycle assessment in the textile sector. Clothing and Textiles Research Journal, 2015. 33(4): p. 231-247.

[28] Behera, B., Comfort and handle behaviour of linen blended fabrics. AUTEX Research Journal, 2007. 7(1): p. 33-47.

[29] Das, B., et al., Moisture transmission through textiles. Part I: processes involved in moisture transmission and the factors at play, AUTEX Research Journal, 2007. 2(7).

[30] Standard, A., D737-04. Test Method for Air Permeability of Textile Fabrics, 2008. 